\title{
A Novel in Vitro Three-Dimensional Macroporous Scaffolds from Bacterial Cellulose for Culture of Breast Cancer Cells
}

\author{
Guangyao Xiong', Honglin Luo ${ }^{2}$, Feng Gu ${ }^{3,4,5}$, Jing Zhang ${ }^{2}$, Da Hü ${ }^{2}$, Yizao Wan ${ }^{2 *}$ \\ ${ }^{1}$ School of Mechanical and Electrical Engineering, East China Jiaotong University, Nanchang, China; ${ }^{2}$ Tianjin Key Laboratory of \\ Composite and Functional Materials, School of Materials Science and Engineering, Tianjin University, Tianjin, China; ${ }^{3}$ Department \\ of Breast Cancer Pathology and Research Laboratory, Tianjin Medical University Cancer Institute and Hospital, Tianjin, China; ${ }^{4}$ Key \\ Laboratory of Breast Cancer Prevention and Therapy, Tianjin Medical University, Ministry of Education, Tianjin, China; ${ }^{5}$ Key \\ Laboratory of Cancer Prevention and Therapy, Tianjin, China. \\ Email: *yzwantju@126.com, ${ }^{*}$ yzwan@tju.edu.cn
}

Received June $15^{\text {th }}, 2013$; revised July $15^{\text {th }}, 2013$; accepted August $2^{\text {nd }}, 2013$

Copyright (C) 2013 Guangyao Xiong et al. This is an open access article distributed under the Creative Commons Attribution License, which permits unrestricted use, distribution, and reproduction in any medium, provided the original work is properly cited.

\begin{abstract}
In this work, patterned macropores with a diameter larger than $100 \mu \mathrm{m}$ were introduced to pristine three-dimensional (3D) nanofibrous bacterial cellulose (BC) scaffolds by using the infrared laser micromachining technique in an attempt to create an in vitro model for the culture of breast cancer cells. The morphology, pore structure, and mechanical performance of the obtained patterned macroporous BC (PM-BC) scaffolds were characterized by scanning electron microscopy (SEM), mercury intrusion porosimeter, and mechanical testing. A human breast cancer cell (MDA-MB-231) line was cultured onto the PM-BC scaffolds to investigate the role of macropores in the control of cancer cell behavior. MTT assay, SEM, and hematoxylin and eosin (H\&E) staining were employed to determine cell adhesion, growth, proliferation, and infiltration. The PM-BC scaffolds were found to be able to promote cellular adhesion and proliferation on the scaffolds, and further to allow for cell infiltration into the PM-BC scaffolds. The results demonstrated that BC scaffolds with laser-patterned macropores were promising for the in vitro 3D culture of breast cancer cells.
\end{abstract}

Keywords: 3D Culture; Scaffold; Bacterial Cellulose; Cancer Cell; Macropore

\section{Introduction}

Tissue engineering, as stated by Langer and Vacanti, is the process of creating functional three-dimensional (3D) tissues using scaffolds or devices that facilitate cell growth, organization, and differentiation [1]. Tumor engineering was described by Ghajar and Bissell as "the construction of complex cell culture models that recapitulate aspects of the in vivo tumor microenvironment to study the dynamics of tumor development, progression, and therapy on multiple scales" [2]. In tissue engineering, a scaffold with in vivo architecture and in vivo microenvironments should be employed in order to create a biological tissue or organ with natural functions. In this context, 3D scaffolds have been widely employed from a biomimetics point of view. The biomimetic strategies have also been employed in tumor engineering in the past few years and thus 3D scaffolds have begun their appli-

*Corresponding author. cations in cancer research [3]. Use of 3D scaffolds in tumor engineering has helped researchers realize that there are significant differences between conventional two-dimensional (2D) petri dish cultures and 3D cultures and the latter can provide an ideal tool for the study of the transformation of normal cells into cancer and tumorigenesis under pathologically relevant culture conditions [4,5]. Furthermore, Bissell et al. commented that appropriate $3 \mathrm{D}$ cultures could provide a more physiologically relevant approach to the analysis of gene function and cell phenotype ex vivo [4] while cancer cells cultured in 2D poorly represented their in vivo physiological conditions. For instance, the ability of malignant cells to grow and metastasize in vivo depends upon specific cell-cell and cell-extracellular matrix (ECM) interactions, many of which are absent when cells are cultured on conventional 2D tissue culture plastic [6]. Additionally, it is well documented that the efficacy of potential anticancer drugs during preclinical development is 
generally tested in vitro using cancer cells grown in scaffolds. Conventional evaluation is based upon the 2D culture; however, a significant discrepancy in their efficacy is observed when these drugs are evaluated in vivo. For instance, Horning et al. declared that the cells grown in 3D scaffolds are more resistant to chemotherapy than those grown in 2D culture [7]. Therefore, creating 3D culture which mimics in vivo conditions is of primary importance to the evaluation of the efficacy of anticancer drugs as well as the study of tumor biology [8].

To date, various biomaterials including natural and synthetic polymers have been used to fabricate 3D scaffolds for cancer research and anticancer drugs tests. Collagen has been widely utilized to culture cells owing to its excellent characteristics, including biocompatibility, mechanical strength, degradability and limited immunogenicity $[9,10]$. Other biomaterials such as chitosanalginate [11], polyacrylamide [12], poly (lactic acid) (PLA) [7,13], poly(lactic-co-glycolide) (PLGA) [7,13], hyaluronan [14], and silk fibroin protein [15] have been explored as 3D models for cancer research.

Over the last two decades, various techniques have been developed to fabricate biomimetic scaffolds for tissue engineering and later for tumor engineering. Electrospinning has been the most widely used technique to create 3D scaffolds composed of nanofibers or mostly sub-microfibers $[16,17]$. Electrospinning is a relatively simple and scalable nanotechnological method for the generation of nanostructured scaffolds that closely mimic the dimensions of collagen fibrils of ECM and a very recent report showed the capability of creating $3 \mathrm{D}$ scaffolds [18]. However, electrospun fibers do not allow proper infiltration of the cells to the core of the scaffolds due to the limited pore size. Another substantial disadvantage is that the diameters of the fibers are usually at the upper limits of the $50-500 \mathrm{~nm}$ range seen in natural ECM [19]. Therefore, scaffolds which allow effective cell seeding and penetration, have controllable fiber diameter in nanoscale and sufficient material properties are highly desirable in both tissue engineering and tumor engineering. These requirements and the tremendous interest in exploring the potency of biomimetic scaffolds have urged researchers to continuously develop more techniques. Molecular self assembly [20] and phase separation [21, 22] have emerged as other promising techniques for the fabrication of 3D nanofibrous scaffolds. Efforts are still being made to find more alternative methodologies so as to simultaneously control morphological, mechanical, and chemical performances of scaffolds.

It is noteworthy that bacterial cellulose (BC), a natural nanofibrous polymer, has attracted more and more attention. $\mathrm{BC}$ is not fabricated by electrospinning; instead it is synthesized extracellularly by the bacterium Acetobacter xylinum. BC has received enormous research interest and the number of reports on $\mathrm{BC}$ has showed a tremendous increase over recent years (reviewed by Petersen and Gatenholm [23], and by Klemm and colleagues [24]). BC nanofibers can have a diameter as small as $10 \mathrm{~nm}$ which is the low limit of natural ECM fibers ranging from 10 to several hundreds of nanometers [19]. BC is superior to plant cellulose (PC) owing to its high purity, 3D morphology, high crystallinity, high tensile strength and modulus (the effective modulus of single fibrils of BC ranged from 79 to $88 \mathrm{GPa}$ versus 29 to $36 \mathrm{GPa}$ for plant cellulose [25]) in combination with a variety of properties such as high water holding capacity, large surface area, and particularly good biocompatibility. For instance, a long-term biocompatibility study conducted by Pertile et al. confirmed that $\mathrm{BC}$ caused a mild and benign inflammatory reaction that decreased along time and did not elicit a foreign body reaction [26]. Very recently, a long-term study on in vivo biocompatibility of $\mathrm{BC}$ has been reported and $\mathrm{BC}$ was defined as a biocompatible material [27]. A latest study by Favi et al. showed that $\mathrm{BC}$ scaffolds were cytocompatible and could support cellular adhesion and proliferation, and allowed for osteogenic and chondrogenic differentiation of equinederived bone marrow mesenchymal stem cells (EqMSCs) [28]. Shi and co-workers declared that BC was a good localized delivery system for bone morphogenetic protein-2 (BMP) and would be a potential candidate in bone tissue engineering [29]. Another study by Saska et al. found that $\mathrm{BC}$ membranes functionalized with osteogenic growth peptide (OGP) and its C-terminal pentapeptide OGP could be used in bone tissue engineering/regeneration [30]. Very recently, BC microstrands were fabricated which could serve as a pathway of nutrition and oxygen to feed the cells in the central region of a macroscopic tissue [31]. Though extensive research has been carried out to determine the potential of $\mathrm{BC}$ as tissue engineering scaffolds, investigation on $\mathrm{BC}$ scaffolds for tumor engineering has been very limited. The only pioneering study on the in vitro culture of cancer cells including the human androgen-independent prostate cancer cell line (PC3 ), murine renal cancer cell line (RENCA), and human breast cancer cell line (MDA-MB-231) on BC scaffolds demonstrated that these cancer cells cultured on $\mathrm{BC}$ did not have observable protrusions indicating undesirable cancer cell responses, which were ascribed to the absence of manufactured large porosity [32].

It has been accepted that pore structure is an essential consideration in the development of scaffolds for tissue engineering and pores must be interconnected and large enough to allow for cell growth, migration and nutrient flow, and for vascularization, new tissue formation and remodeling so as to facilitate host tissue integration upon 
implantation. Furthermore, pore volume (porosity), shape and distribution also should be considered [33]. A recent study demonstrated that the acrylate copolymers-based scaffolds with aligned channels achieved a uniform colonization by neural cells [34]. Our previous work indicated that the $\mathrm{BC} /$ Gelatin/Hydroxyapatite scaffolds with patterned pores supported the attachment and proliferation of chondrogenic rat cell [35]. However, how the aligned pore channels affect cancer cell behavior has not been reported.

Therefore, the purpose of the present study was, for the first time, to determine the feasibility of the BC scaffolds with aligned channels as effective in vitro cancer models. To this end, the BC scaffolds with patterned macropores (with a diameter greater than $100 \mu \mathrm{m}$ according to literatures $[33,36])$ were fabricated by an infrared laser micromachining technique and a human breast cancer cell line (MDA-MB-231), as a model cancer cell line, was seeded onto the $3 \mathrm{D}$ macroporous $\mathrm{BC}$ scaffolds to investigate the cancer cellular responses to the scaffolds. The cell behavior on these 3D macroporous $\mathrm{BC}$ scaffolds was compared with that on the pristine $\mathrm{BC}$ scaffolds [32].

\section{Materials and Methods}

\subsection{Materials}

The reagents used in this work included glucose, peptone, yeast extract, disdium phosphate and acetate acid (Acros, Biochemical), deionized water (Aqoapro CO., Ltd, Chongqing, China), sodium hydroxide, ethyl alcohol, formaldehyde, glutaraldehyde, sodium chloride (Tianjin Tianda Tianlong Sci. \& Tech. Co., Ltd., Tianjin, China), hank's balanced salt solution (HBSS), phosphate buffered saline (PBS), dimethyl sulfoxide (DMSO, Gibco), and gelatin (Sigma, analytical grade). All chemicals were used as received without further purification.

\subsection{Preparation of BC Pellicles}

The preparation and purification procedures of $\mathrm{BC}$ pellicles were described previously [37,38]. Briefly, the bacterial strain, Acetobacter xylinum X-2, was grown in the culture media containing $0.3 \mathrm{wt} \%$ green tea powder (analytical grade) and $5 \mathrm{wt} \%$ sucrose (analytical grade) for 7 days. The $\mathrm{pH}$ of the medium was adjusted to 4.5 by acetic acid. BC pellicles were purified by soaking in deionized water at $90^{\circ} \mathrm{C}$ for $2 \mathrm{~h}$ followed by boiling in a 0.5 $\mathrm{M} \mathrm{NaOH}$ solution for $15 \mathrm{~min}$. The $\mathrm{BC}$ pellicles with 9 $\mathrm{cm}$ in diameter were then washed with deionized water several times and soaked in $1 \% \mathrm{NaOH}$ for 2 days. Finally, the $\mathrm{BC}$ pellicles were washed free of alkali.

\subsection{Preparation of 3D BC Scaffolds with Patterned Macropores via Laser Technology}

Many previous studies reported the creation of patterned pores in solid materials such as titanium $[39,40]$, and biodegradable polymers [41-43] mostly by using ultraviolet (UV) or femtosecond laser micromachining. In this study, patterned pores in BC hydrogels were created by using infrared laser. Figure 1 illustrates the laser-micromachining process. The predetermined patterns (including distance between neighboring pores and pore diameter) were initially designed by a commercial CAD software and input to a computer. The $\mathrm{BC}$ hydrogels were then perforated using a $\mathrm{CO}_{2}$ excimer laser (wavelength $10.6 \mu \mathrm{m}$ ) according to the designed patterns to obtain $\mathrm{BC}$ scaffolds with patterned macropores (named as PM-BC hereinafter). The laser generated a stable power of $80 \mathrm{~W}$, the exposure time was about $1-2 \mathrm{~s}$ for every pore depending on the thickness of the $\mathrm{BC}$ samples and the pore diameter could be altered by adjusting the distance between specimens and laser focus (i.e. parameter $d$ in Figure 1). In this work, three PM-BC scaffolds with different pore size and pore density were fabricated and

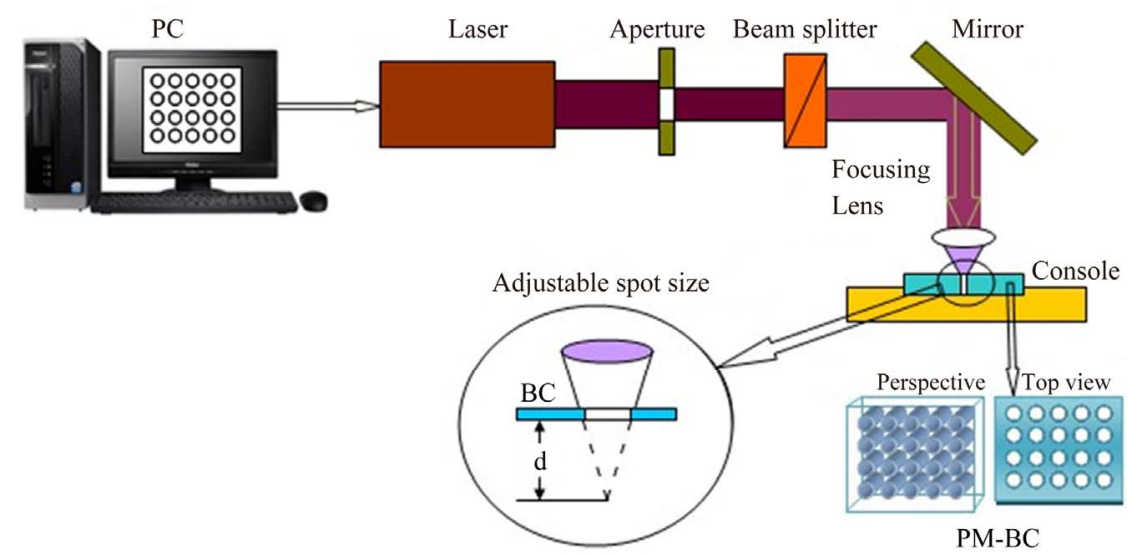

Figure 1. Schematic setup of the laser-patterning system used in this work (the parameter $d$ refers to the distance from laser focus to the specimen). 
their designations and parameters are listed in Table $\mathbf{1 .}$ The resultant PM-BC scaffolds, as well as the pristine BC scaffolds without macropores, were immersed into deionized water for $2 \mathrm{~h}$ and then washed with distilled water for several times.

\subsection{Scaffold Characterization}

\subsubsection{Field Emission Scanning Electron Microscopy (FE-SEM)}

The morphology of the PM-BC scaffolds was observed by using a Nano 430 field emission scanning electron microscope (FE-SEM), FEI, USA. For FE-SEM observations, samples were sputter coated with gold and were observed at an accelerating voltage of $10 \mathrm{kV}$.

\subsubsection{Mercury Porosimeter}

The pore size distribution and porosity of the BC scaffolds were determined by a PoreMaster 60 GT mercury intrusion porosimeter (Quantachrome) that could measure pore diameter ranging from $950 \mu \mathrm{m}$ to up to $3.6 \mathrm{~nm}$.

\subsubsection{Mechanical Testing}

The tensile properties of PM-BC and pristine BC samples in the wet state were determined using a Testometric universal testing machine M350 (Testometric Co. Ltd., United Kingdom) in accordance with ASTM D 638-98 under ambient temperature and humidity $\left(20^{\circ} \mathrm{C} / 65 \% \mathrm{RH}\right)$ with a constant crosshead speed of $5 \mathrm{~mm} / \mathrm{min}$. The tensile modulus was determined from the linear region of stress-strain curves. The Young's modulus, tensile strength, and strain at break were determined from at least five samples.

\subsection{Cell Studies}

\subsubsection{MTT Proliferation Assay}

The cell proliferation was evaluated by the colorimetric MTT assay. Firstly, the human breast cancer cell line (MDA-MB-231) was maintained in DMEM (Gibco) with $10 \%$ FBS (Gibco) at $37^{\circ} \mathrm{C}$ in a $5 \% \mathrm{CO}_{2}$ incubator. Monolayer MDA-MB-231 cells were harvested by trypsin/EDTA treatment. Before cell seeding, cylindrical BC scaffolds $(\Phi 10 \times 1 \mathrm{~mm})$ were sterilized with UV radiation. After sterilization, the scaffolds were pre-soaked in

Table 1. The designation of various samples prepared in this work.

\begin{tabular}{ccc}
\hline Sample No. & $\begin{array}{c}\text { Designed pore diameter } \\
(\mu \mathrm{m})\end{array}$ & $\begin{array}{c}\text { Designed pore distance } \\
(\mathrm{mm})\end{array}$ \\
\hline PM-BC-1 & 150 & 1.0 \\
PM-BC-2 & 150 & 1.5 \\
PM-BC-3 & 300 & 1.5 \\
\hline
\end{tabular}

DMEM for at least $12 \mathrm{~h}$. Subsequently, the scaffolds were incubated in 24-well tissue culture plates with MDA-MB-231 cells at a density of $2 \times 10^{5}$ cell $/ \mathrm{mL}$ for 1 , 3,5 and 7 days at $37^{\circ} \mathrm{C}$ in $5 \% \mathrm{CO}_{2}$ incubator. After incubation, the cell-scaffold constructs were rinsed with PBS to remove non-adhering cells, followed by incubation in $50 \mu \mathrm{L}$ MTT reagent for $4 \mathrm{~h}$ under the same conditions as described above. After removal of the media, $500 \mu \mathrm{L}$ of DMSO was added to the wells to dissolve the converted dye. The solution $(150 \mu \mathrm{L})$ from each sample was transferred to 96-well plates and the optical density (O.D.) was measured with an ELISA reader (BIORAD, Munich, Germany) at an absorbance of $490 \mathrm{~nm}$.

\subsubsection{Cell Imaging}

Cell morphology study on PM-BC-3 scaffold was carried out by FE-SEM. After pre-soaking with DMEM overnight, PM-BC-3 samples $(\Phi 10 \times 1 \mathrm{~mm})$ were incubated with MDA-MB-231 cells at a density of $2 \times 10^{5}$ cell $/ \mathrm{mL}$ in 24-well plates for 14 days at $37^{\circ} \mathrm{C}$ in $5 \% \mathrm{CO}_{2}$. After 14 days incubation, the cell-scaffold samples were rinsed twice with PBS and fixed using 4\% glutaraldehyde for 12 $\mathrm{h}$, and then dehydrated through gradient concentration of ethanol a series of graded alcohols $(40 \%, 50 \%, 60 \%$, $70 \%, 80 \%, 90 \%$ and $100 \%$ ), and air-dried. Finally, the samples were sputter-coated with a layer of gold as described above and observed by SEM to analyze cell adhesion and morphology.

\subsubsection{Histological Analysis}

After 3, 7, 14, 21, and 28 days culture, the cell-scaffold constructs were washed with ice-cold normal saline $(0.9 \% \mathrm{NaCl})$, cut transversely into thin slices $(5 \mu \mathrm{m})$, and then fixed into $10 \%$ neutral-buffered formaldehyde for $24 \mathrm{~h}$. The tissues were then transferred into $70 \%$ ethyl alcohol, processed, and embedded in paraffin wax. The sections with cells were stained with hematoxylin and eosin (H\&E) for histological examination using a Zeiss Axioplan-2 fluorescence light microscope (Carl Zeiss, Inc., NY).

\subsection{Statistical Analysis}

All experiments were performed in triplicate unless otherwise stated. Statistical analysis of data was performed using an SPSS system. All data were presented as mean values \pm standard deviation (SD). Results with $p$-values of $<0.05$ were considered statistically significant.

\section{Results and Discussion}

\subsection{Morphology of the PM-BC Scaffolds}

Figure 2 shows the optical and SEM images of three PM-BC scaffolds. Note that aligned channels were cre- 


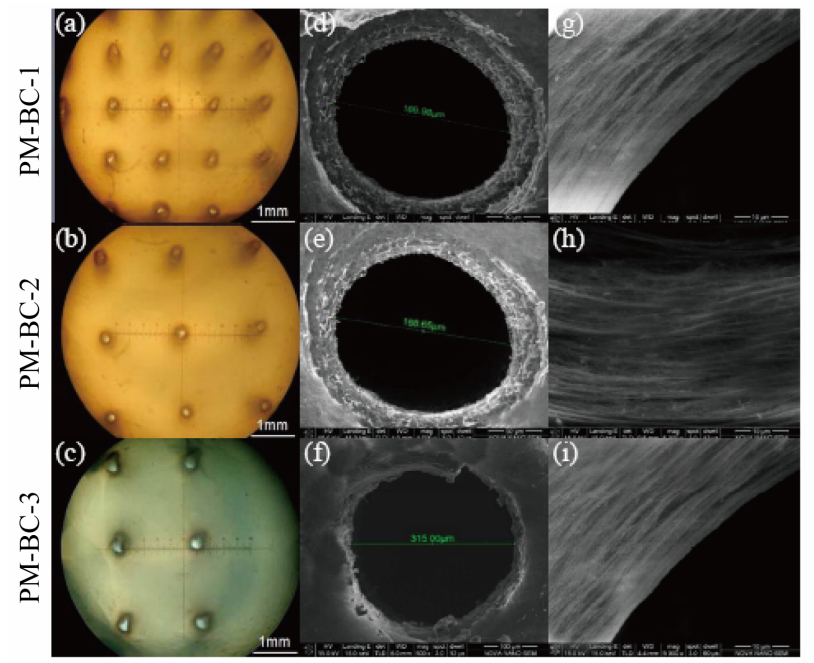

Figure 2. Optical (a)-(c) and SEM (d)-(i) photos of PM-BC1 (a), (d), (g), PM-BC-2 (b), (e), (h), and PM-BC-3 (c), (f), (i).

ated in the BC scaffolds by computer-aided laser patterning technique and that both the density and diameter of the patterned macropores were controllable (Figures 2(a)-(c)). As displayed in Figures 2(d)-(f), the obtained pore diameter was about 170, 169, and $315 \mu \mathrm{m}$ for PMBC-1, PM-BC-2, and PM-BC-3, respectively, which was 15 - $20 \mu \mathrm{m}$ larger than the designed values. High magnification SEM images (Figures 2(g)-(i)) revealed that the wall of each macropore was smooth without any debris that was often observed for UV and femtosecond laser micromachining. Figures 2(g)-(i) also showed that the wall of each macropore was porous, consisting of nanofibers and micropores $(<100 \mu \mathrm{m}$ as defined in the literature $[33,36])$ and nanopores $(<100 \mathrm{~nm})$ (see Section 3.2), which was actually the intrinsic characteristics of pristine BC [44]. This structural feature was very favorable to the cell functions since porous wall favored cell functions [45] while compact pore walls hindered metabolite diffusion thus restricting cell proliferation and migration inside 3D scaffolds [46]. In other words, when cells were seeded onto the internal porous matrix of PM-BC scaffolds, the inner porous wall was believed to be able to keep deeply embedded cells supplied with nutrients [47].

\subsection{Pore Size Distribution}

Scaffold pore structure included porosity, pore size, pore geometry, pore branching, pore connectivity and pore orientation [33]. Though SEM revealed the co-existence of macropores $(>100 \mu \mathrm{m})$, micropores, and nanopores in the PM-BC scaffolds, porosity and pore size distribution could not be obtained by SEM. In this work, mercury intrusion porosimeter was used to obtain porosity and pore size and its distribution of the pristine $\mathrm{BC}$, and the pore volume percentage and porosity of three PM-BC scaffolds were thus obtained. The results are listed in Table 2. As could be seen from this table, the dominant pores in the pristine $\mathrm{BC}$ scaffold were in the range of 10 to $100 \mu \mathrm{m}$ (mostly at ca. $20 \mu \mathrm{m}$ ) and a few nanopores with a diameter of $4-6 \mathrm{~nm}$ were also observed. This small pore size might interpret the poor cell adhesion, proliferation, and non-infiltration to the inner side of the pristine BC scaffolds reported by Szot et al. [32]. It was noted that a significantly different pore structure was observed for PM-BC scaffolds. Three PM-BC scaffolds contained macropores in addition to nanopores and micropores. Though all the four samples showed hierarchical pore structure, the three PM-BC samples showed a much wider pore diameter distribution because of the existence of macropores, which would be beneficial to the culture of cells as macropores were favorable to cell migration and particularly for cell infiltration to the core of scaffolds.

It was reported that a combination of large and small pores was necessary for tissue engineering scaffolds because the large pores acted as the passage of nutrients and wastes and provided the areas where different celltypes can be deposited, while the small pores favored to provide correct signals to encourage differentiation and to pattern cells as they differentiate into an organized tissue [47]. A study on multi-layered 3D scaffolds consisting of microchannels $(250 \mu \mathrm{m})$ and inner smaller pores $(<10 \mu \mathrm{m})$ confirmed the notion [48]. As cancer cells usually had a larger size than normal tissue cells, the existence of large pores would be mandatory for cancer cell metastasis in addition to small pores.

\subsection{Tensile Properties}

Figure 3 shows the tensile strength and modulus, and strain at break of three $\mathrm{PM}-\mathrm{BC}$ and pristine $\mathrm{BC}$ samples. As expected, all three $\mathrm{PM}-\mathrm{BC}$ exhibited significantly lower tensile strength ( $p<0.05$ in all cases) than pristine $\mathrm{BC}$ and PM-BC-1 had significantly lower tensile modulus and strain $(p<0.05)$ than pristine $\mathrm{BC}$. However, the differences in tensile modulus and strain between pristine $\mathrm{BC}$ and $\mathrm{PM}-\mathrm{BC}-2$ and $\mathrm{PM}-\mathrm{BC}-3$ were not significant $(p>0.05)$, indicating that tensile strength was more sensitive to macropores as compared to tensile modulus and strain. The significantly lower tensile modulus and strain of PM-BC-1 than PM-BC-2, PM-BC-3, and pristine $\mathrm{BC}$ was simply due to its higher pore density in comparison to other two PM-BC samples (comparing pore distance listed in Table 1), suggesting that the modulus and strain of porous scaffolds were not merely controlled by pore volume, instead they were also relevant to pore density.

Although about $12 \%$ reduction in tensile strength was 
Table 2. Comparisons of pore volume percentage (\%) and porosity (\%) of various BC scaffolds.

\begin{tabular}{|c|c|c|c|c|c|}
\hline \multirow{2}{*}{ Samples } & \multirow{2}{*}{$\begin{array}{l}\text { Nanopores (\%) } \\
\quad<100 \mathrm{~nm}\end{array}$} & \multicolumn{2}{|c|}{ Micropores (\%) } & \multirow{2}{*}{$\begin{array}{l}\text { Macropores (\%) } \\
\quad>100 \mu \mathrm{m}\end{array}$} & \multirow{2}{*}{ Porosity (\%) } \\
\hline & & $1-10 \mu \mathrm{m}$ & $10-100 \mu \mathrm{m}$ & & \\
\hline Pristine BC & 1.36 & 25.19 & 66.81 & 0.00 & 92.05 \\
\hline PM-BC-1 & 1.33 & 23.88 & 65.95 & 1.28 & 92.16 \\
\hline PM-BC-2 & 1.30 & 24.65 & 65.38 & 2.14 & 92.23 \\
\hline PM-BC-3 & 1.30 & 24.08 & 63.88 & 4.38 & 92.44 \\
\hline
\end{tabular}
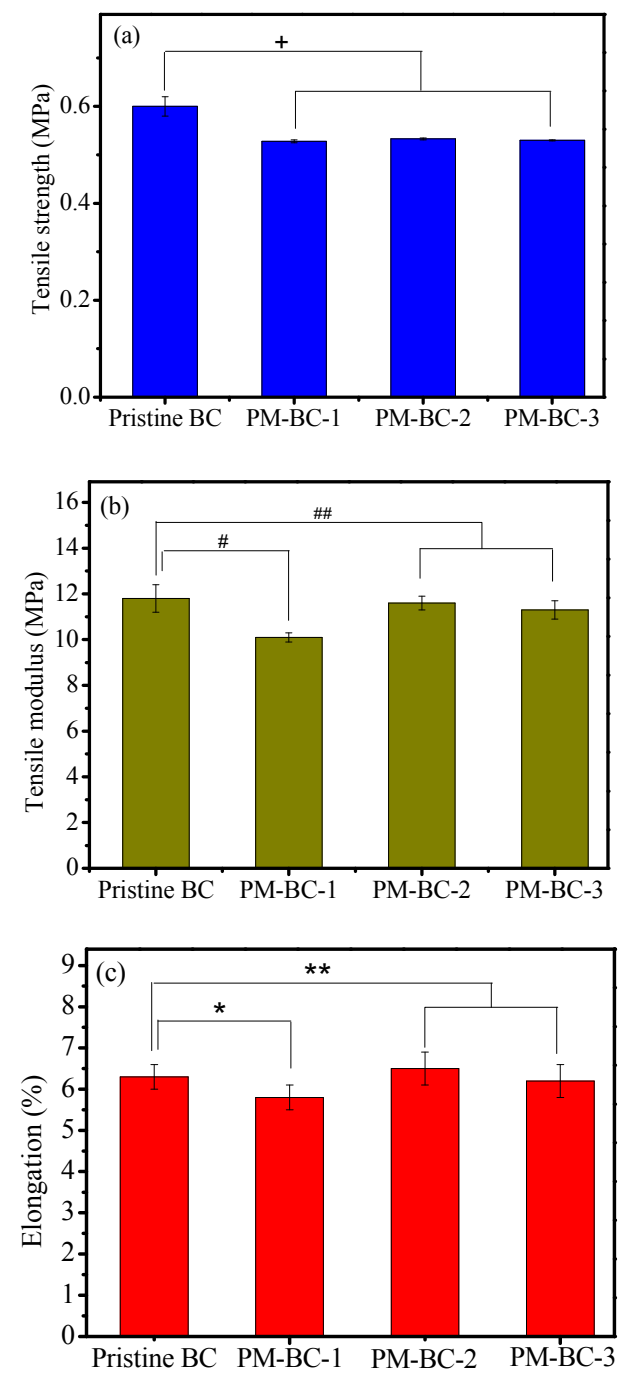

Figure 3. Tensile strength (a), tensile modulus (b), and strain at break (c) of various materials $\left(p^{+}, p^{\#}\right.$, and $p^{*}<0.05 ; p^{\# \#}$ and $\left.p^{* *}>0.05\right)$.

observed because of the creation of macropores, the tensile strength value of these PM-BC samples was still much higher than other natural biomaterials. For instance, it was 40-fold higher than hyaluronan-collagen scaffolds $(10-15 \mathrm{kPa})$ [49]. Tensile testing indicated that the presence of macropores did not sharply decrease the tensile properties of BC samples, which made the PM-BC scaf- folds still very competitive for tissue engineering and tumor engineering scaffolds in terms of mechanical performances.

Many previous studies on bone tissue engineering have suggested a need for pore size $>300 \mu \mathrm{m}$ for bone formation and vascularisation [40,45,50]. Considering cancer cells are usually larger in size than normal cells, PM-BC-3 with $315 \mu \mathrm{m}$ pore size was believed to be a more suitable candidate for cancer cell culture in comparison to PM-BC-1 and PM-BC-2. Furthermore, PMBC-3 demonstrated higher tensile properties than PMBC-1 and comparable to PM-BC-2. Therefore, PM-BC-3 was used in the subsequent cell studies.

\subsection{Cell Viability and Proliferation}

The MTT assay result shown in Figure $\mathbf{4}$ demonstrated that cancer cells were viable and the proliferation of MDA-MB-231 cell line was robust, keeping a constant rate during 7 days culture. However, limited viability and proliferation were observed by Szot et al. when cancer cells were cultured on the pristine $\mathrm{BC}$ without introduction of macropores [32]. The difference in cell proliferation suggested that the pore structure and size of the tumor engineering scaffolds were crucial to the culture of cancer cells.

\subsection{Morphology of Cells on the PM-BC-3 Scaffold}

Previous study by Szot et al. demonstrated that cancer cells cultured on BC were not spread out across the surface of $\mathrm{BC}$ scaffolds due to the absence of manufactured porosity [32]. In this study, adhesion and morphology of the MDA-MB-231 cells after 7 days seeding on the PMBC-3 scaffold were characterized by SEM and the results are shown in Figure 5. SEM demonstrated that cancer cells were attached to the scaffold. Note that individual cancer cell and cancer cell aggregates attached and spread throughout the surface of the PM-BC-3 scaffold and many cells connected to the neighboring cells as shown in Figures 5(a) and (b). Figures 5(c) and (d) demonstrated a wide spread and tight attachment to the scaffold. Furthermore, the MDA-MB-231 cells on the PM-BC 


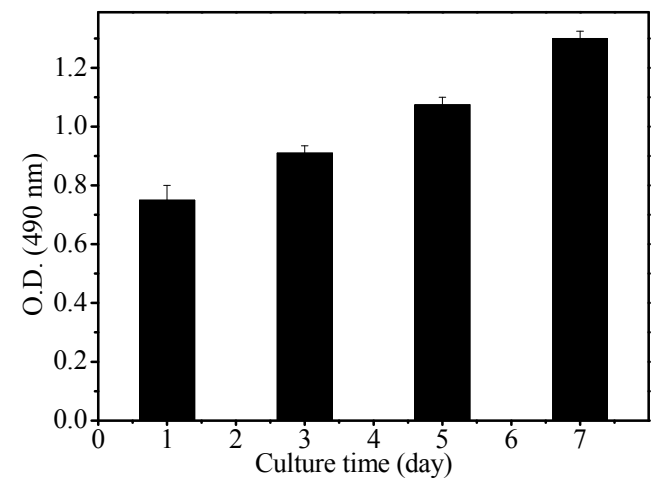

Figure 4. Proliferation of MDA-MB-231 cell line cultured on the PM-BC scaffold by MTT assay.
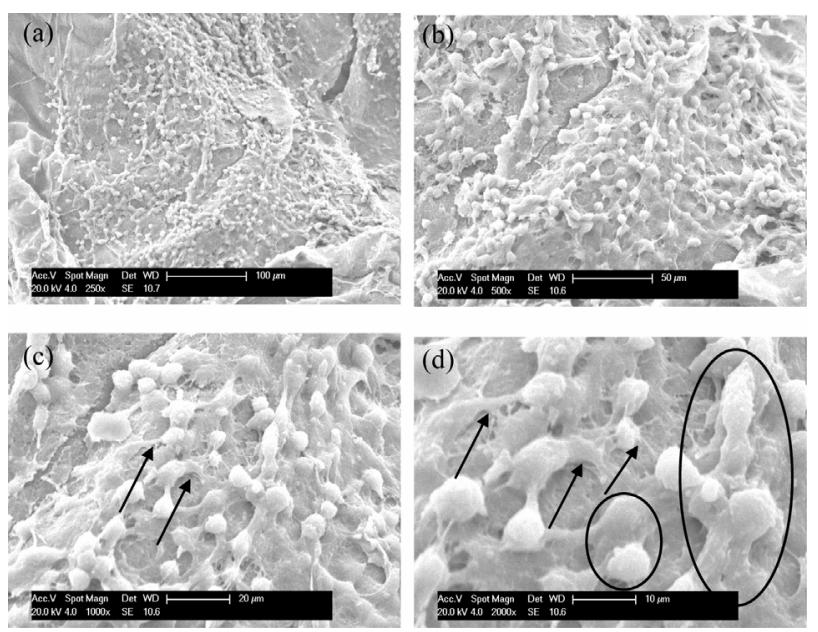

Figure 5. SEM images of MDA-MB-231 cells on the PM-BC scaffold after 2 weeks culture ((a)-(d) showing varying magnification).

scaffold kept their normal morphology of roughly rounded shape (3D image: oblate spheroid), which was similar to that seen in cells grown on chitosan-alginate (CA) 3D scaffolds reported by Kievit et al. who declared that cells in solid tumors exhibit similar morphology and thus concluded that the CA scaffolds could provide a growth environment that promoted the formation of solid tumorlike cells [11]. More importantly, a large number of protruded pseudopodiums were formed that bonded to the scaffold (see arrows in Figures 5(c) and (d)), indicating a strong adhesion of cancer cells to the scaffold. It was striking to note that multilayered cancer cells were observed on the surface of the PM-BC scaffold (circle in Figure 5(d)) and moreover, cancer cells in the basal layer formed clusters (ellipse in Figure 5(d)), which could never be found for conventional $2 \mathrm{D}$ culture due to its limited space. The SEM results suggested that the PMBC-3 scaffold strongly supported the adhesion, spreading, proliferation, and differentiation of the MDA-MB-231 cell line.

\subsection{Histological Observation}

SEM observation was not able to provide any information inside the scaffold. In this study, histological observation was performed to evaluate the cells distribution inside the PM-BC scaffold upon culture for varying periods up to 4 weeks. The H\&E staining results are shown in Figure 6. Szot and co-workers reported that no cancer cell infiltration was observed after 7 days culture on BC [32] while the results of the present study were totally different. As clearly seen in Figure 6(A), the distribution of the MDA-MB-231 cells within the PM-BC-3 scaffold was observed, suggesting cells migration into the macroporous scaffold and further formed clusters in some areas (circles in Figures 6(A-b) and (A-c)) even after only 3 days culture. After 7 days culture (Figure 6(B)), the cells spread and grew along the walls of the macropores (see arrows in Figure 6(B)) and more cell clusters were found (see circle in Figure 6(B-c)), indicating successive growth and proliferation inside the PM-BC-3 scaffold. Figures 6(A) to (E) clearly showed an increased cell density and increased number of clusters (Figure 6(E-c) as a representative) with culture time, indicating that cancer cells experienced robust proliferation, in-growth, and differentiation inside the PM-BC-3 scaffold. These findings suggested that cancer cells could penetrate into the core of the PM-BC-3 scaffold due to the presence of macropores. The histological observation together with the SEM and MTT results was sufficient to verify that the PM-BC-3 scaffold was able to promote the adhesion, in-growth, proliferation, and differentiation of the MDA-MB-231 cells and thus this macroporous material could be a novel scaffold for the in vitro culture of cancer cells.

\section{Conclusion}

Patterned macroporous BC scaffolds were successfully prepared by a one-step direct perforation in $\mathrm{BC}$ hydrogels by using infrared laser micromachining technique. The PM-BC scaffolds with different pore size and pore density could be obtained. Mechanical tests revealed that the PM-BC scaffolds could maintain 88 percent tensile strength of the pristine $\mathrm{BC}$ scaffolds and insignificant difference in tensile modulus and strain at break were observed between the pristine $\mathrm{BC}$ and two PM-BC samples with pore distance of $1.0 \mathrm{~mm}$. All three PM-BC scaffolds prepared in this work showed hierarchical pore size distribution from several nanometers to over a hundred microns, but the PM-BC-3 scaffold showed the largest pore size $(315 \mu \mathrm{m})$ and porosity and the widest pore size distribution among the three macroporous $\mathrm{BC}$ scaffolds. It was concluded that, similar to UV and femtosecond lasers which were suitable for metals and polymers, the infrared laser was an excellent tool for 


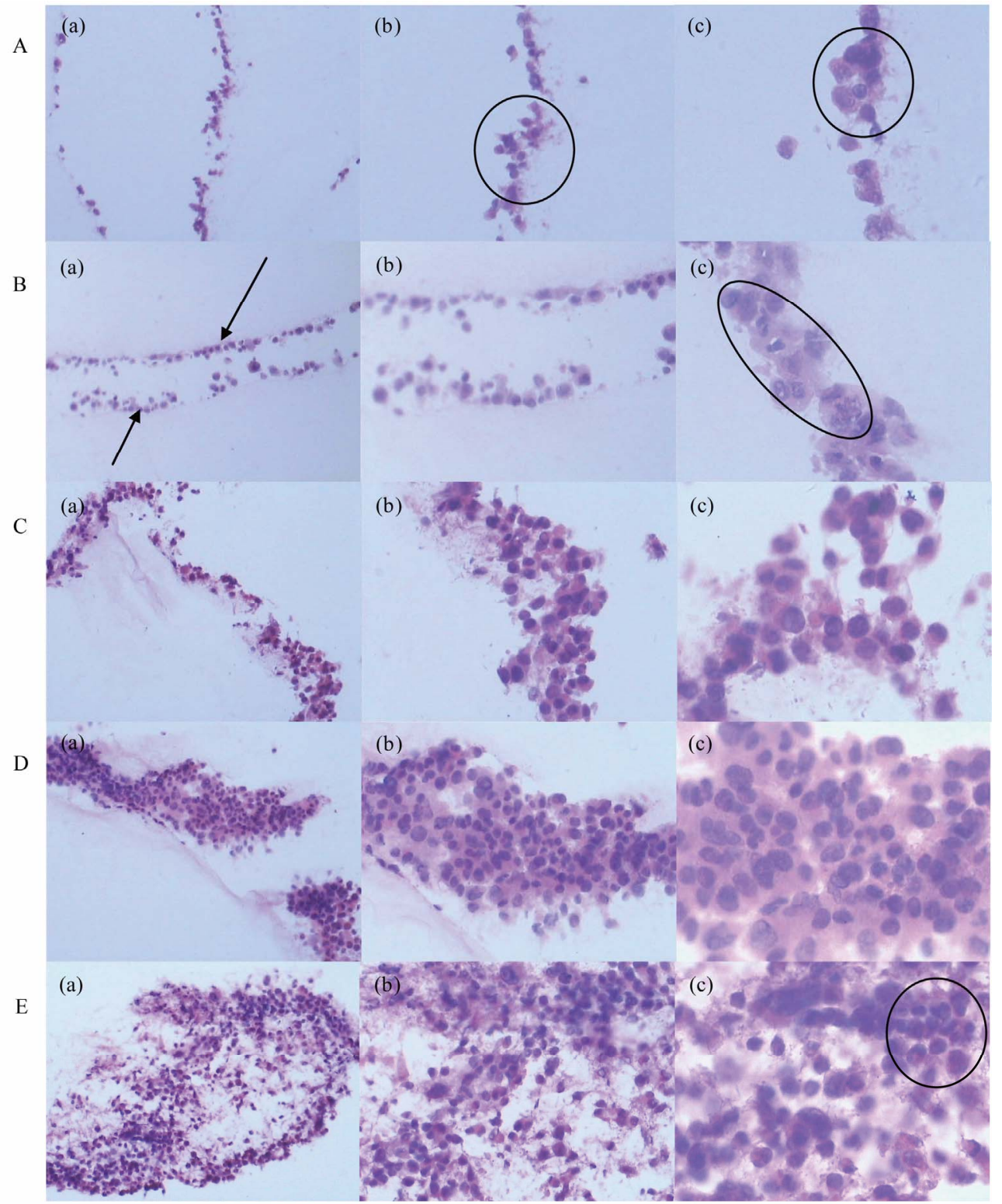

Figure 6. Histological analysis of MDA-MB-231 cell line grown in PM-BC-3 scaffold 3 (A), 7 (B), 14 (C), 21 (D) and 28 (E) days post-seeding.

macropatterning $\mathrm{BC}$ hydrogels as a rapid and chemical free process and thus showed a great potential in macromachining other hydrogels. Results of the cell proliferation assay with almost linear growth suggested that the PM-BC-3 scaffold could support the growth and proliferation of MDA-MB-231 cell line. SEM indicated that the MDA-MB-231 cells on the PM-BC-3 scaffold kept their normal morphology and that multilayered growth was noted. Both SEM and histological analysis revealed the existence of cell clusters. Additionally, histological analysis revealed that cells attached and infiltrated into the PM-BC-3 scaffold 3 days post-seeding. Cell studies with the PM-BC-3 scaffold showed that this laser-pat- terned macroporous scaffold exhibited good cell compatibility, could promote cell adhesion and spread on the scaffold surface, and cells were able to proliferate within the scaffold, indicating the satisfactory biocompatibility of the macroporous scaffold.

\section{Acknowledgements}

This work is supported by the National Natural Science Foundation of China (Grants No. 51172158, 81272358, 30930038 and 81200663) and the Science and Technology Support Program of Tianjin (Grant No. 11ZCKFSY01700). 


\section{REFERENCES}

[1] R. Langer and J. P. Vacanti, "Tissue Engineering," Science, Vol. 260, No. 5110, 1993, pp. 920-926. http://dx.doi.org/10.1126/science.8493529

[2] C. M. Ghajar and M. J. Bissell, "Tumor Engineering: The Other Face of Tissue Engineering," Tissue Engineering Part A, Vol. 16, No. 7, 2010, pp. 2153-2156. http://dx.doi.org/10.1089/ten.tea.2010.0135

[3] Y. Aizawa, S. C. Owen and M. S. Shoichet, "Polymers Used to Influence Cell Fate in 3D Geometry: New Trends," Progress in Polymer Science, Vol. 37, No. 5, 2012, pp. 645-658.

http://dx.doi.org/10.1016/j.progpolymsci.2011.11.004

[4] G. Y. Lee, P. A. Kenny, E. H. Lee and M. J. Bissell, "Three-Dimensional Culture Models of Normal and Malignant Breast Epithelial Cells," Nature Methods, Vol. 4, No. 4, 2007, pp. 359-365. http://dx.doi.org/10.1038/nmeth1015

[5] C. Fischbach, R. Chen, T. Matsumoto, T. Schmelzle, J. S. Brugge, P. J. Polverini and D. J. Mooney, "Engineering Tumors with 3D Scaffolds," Nature Methods, Vol. 4, No. 10, 2007, pp. 855-860. http://dx.doi.org/10.1038/nmeth1085

[6] M. A. Cichon, V. G. Gainullin, Y. Zhang and D. C. Radisky, "Growth of Lung Cancer Cells in Three-Dimensional Microenvironments Reveals Key Features of Tumor Malignancy," Integrative Biology, Vol. 4, No. 4, 2012, pp. 440-448. http://dx.doi.org/10.1039/c1ib00090j

[7] J. L. Horning, S. K. Sahoo, S. Vijayaraghavalu, S. Dimitrijevic, J. K. Vasir, T. K. Jain, A. K. Panda and V. Labhasetwar, "3-D Tumor Model for in Vitro Evaluation of Anticancer Drugs," Molecular Pharmacology, Vol. 5, No. 5, 2008, pp. 849-862. http://dx.doi.org/10.1021/mp800047v

[8] M. Mitra, C. Mohanty, A. Harilal, U. K. Maheswari, S. K. Sahoo and S. Krishnakumar, "A Novel in Vitro ThreeDimensional Retinoblastoma Model for Evaluating Chemotherapeutic Drugs," Molecular Vision, Vol. 18, No. 142-145, 2012, pp. 1361-1378.

[9] L. Chen, Z. Xiao, Y. Meng, Y. Zhao, J. Han, G. Su, B. Chen and J. Dai, "The Enhancement of Cancer Stem Cell Properties of MCF-7 Cells in 3D Collagen Scaffolds for Modeling of Cancer and Anti-Cancer Drugs," Biomaterials, Vol. 33, No. 5, 2012, pp. 1437-1444. http://dx.doi.org/10.1016/j.biomaterials.2011.10.056

[10] C. S. Szot, C. F. Buchanan, J. W. Freeman and M. N. Rylander, "3D in Vitro Bioengineered Tumors Based on Collagen I Hydrogels," Biomaterials, Vol. 32, No. 31, 2011, pp. 7905-7912.

http://dx.doi.org/10.1016/j.biomaterials.2011.07.001

[11] F. M. Kievit, S. J. Florczyk, M. C. Leung, O. Veiseh, J. O. Park, M. L. Disis and M. Zhang, "Chitosan-Alginate 3D Scaffolds as a Mimic of the Glioma Tumor Microenvironment," Biomaterials, Vol. 31, No. 22, 2010, pp. 59035910. http://dx.doi.org/10.1016/j.biomaterials.2010.03.062

[12] K. A. Beningo, M. Dembo and Y. Wang, "Responses of Fibroblasts to Anchorage of Dorsal Extracellular Matrix
Receptors," Proceedings of the National Academy of Sciences of the United States of America, Vol. 101, No. 52, 2004, p. 18024.

http://dx.doi.org/10.1073/pnas.0405747102

[13] S. K. Sahoo, A. K. Panda and V. Labhasetwar, "Characterization of Porous PLGA/PLA Microparticles as a Scaffold for Three Dimensional Growth of Breast Cancer Cells," Biomacromolecules, Vol. 6, No. 2, 2005, pp. 1132-1139. http://dx.doi.org/10.1021/bm0492632

[14] N. Rhodes, J. Srivastava, R. Smith and C. Longinotti, "Metabolic and Histological Analysis of Mesenchymal Stem Cells Grown in 3-D Hyaluronan-Based Scaffolds," Journal of Materials Science: Materials in Medicine, Vol. 15, No. 4, 2004, pp. 391-395. http://dx.doi.org/10.1023/B:JMSM.0000021108.74004.7e

[15] S. Talukdar, M. Mandal, D. W. Hutmacher, P. J. Russell, C. Soekmadji and S. C. Kundu, "Engineered Silk Fibroin Protein 3D Matrices for in Vitro Tumor Model," Biomaterials, Vol. 32, No. 8, 2010, pp. 2149-2159. http://dx.doi.org/10.1016/j.biomaterials.2010.11.052

[16] J. Lannutti, D. Reneker, T. Ma, D. Tomasko and D. F. Farson, "Electrospinning for Tissue Engineering Scaffolds," Materials Science and Engineering C, Vol. 27, No. 3, 2007, pp. 504-509. http://dx.doi.org/10.1016/j.msec.2006.05.019

[17] S. Agarwal, J. H. Wendorff and A. Greiner, "Progress in the Field of Electrospinning for Tissue Engineering Applications," Advanced Materials, Vol. 21, No. 32-33, 2009, pp. 3343-3351. http://dx.doi.org/10.1002/adma.200803092

[18] W. Yang, F. Yang, Y. Wang, S. K. Both and J. A. Jansen, "In Vivo Bone Generation via the Endochondral Pathway on Three-Dimensional Electrospun Fibers," Acta Biomaterialia, Vol. 9, No. 1, 2013, pp. 4505-4512. http://dx.doi.org/10.1016/j.actbio.2012.10.003

[19] T. Dvir, B. P. Timko, D. S. Kohane and R. Langer, "Nanotechnological Strategies for Engineering Complex Tissues," Nature Nanotechnology, Vol. 6, No. 1, 2011, pp. 13-22. http://dx.doi.org/10.1038/nnano.2010.246

[20] T. G. Kim, H. Shin and D. W. Lim, "Biomimetic Scaffolds for Tissue Engineering," Advanced Functional Materials, Vol. 22, No. 12, 2012, pp. 2446-2468. http://dx.doi.org/10.1002/adfm.201103083

[21] C. Vaquette and J. Cooper-White, "A Simple Method for Fabricating 3-D Multilayered Composite Scaffolds," Acta Biomaterialia, Vol. 9, No. 1, 2013, pp. 4599-4608. http://dx.doi.org/10.1016/j.actbio.2012.08.015

[22] J. Mao, S. Duan, A. Song, Q. Cai, X. Deng and X. Yang, "Macroporous and Nanofibrous Poly(Lactide-co-Glycolide)(50/50) Scaffolds via Phase Separation Combined with Particle-Leaching," Materials Science and Engineering $C$, Vol. 32, No. 6, 2012, pp. 1407-1414. http://dx.doi.org/10.1016/j.msec.2012.04.018

[23] N. Petersen and P. Gatenholm, "Bacterial CelluloseBased Materials and Medical Devices: Current State and Perspectives," Applied Microbiology and Biotechnology, Vol. 91, No. 5, 2011, pp. 1277-1286. http://dx.doi.org/10.1007/s00253-011-3432-y 
[24] D. Klemm, F. Kramer, S. Moritz, T. Lindstrom, M. Ankerfors, D. Gray and A. Dorris, "Nanocelluloses: A New Family of Nature-Based Materials," Angewandte Chemie International Edition, Vol. 50, No. 24, 2011, pp. 54385466. http://dx.doi.org/10.1002/anie.201001273

[25] S. Tanpichai, F. Quero, M. Nogi, H. Yano, R. J. Young, T. Lindstrom, W. W. Sampson and S. J. Eichhorn, "Effective Young's Modulus of Bacterial and Microfibrillated Cellulose Fibrils in Fibrous Networks," Biomacromolecules, Vol. 13, No. 5, 2012, pp. 1340-1349. http://dx.doi.org/10.1021/bm300042t

[26] R. A. N. Pertile, S. Moreira, R. M. Gil da Costa, A. Correia, L. Guardao, F. Gartner, M. Vilanova and M. Gama, "Bacterial Cellulose: Long-Term Biocompatibility Studies," Journal of Biomaterials Science Polymer Edition, Vol. 23, No. 10, 2012, pp. 1339-1354.

[27] F. K. Andrade, N. Alexandre, I. Amorim, F. Gartner, A. C. Maurício, A. L. Luís and M. Gama1, "Studies on the Biocompatibility of Bacterial Cellulose," Journal of Bioactive and Compatable Polymers, Vol. 28, No. 1, 2013, pp. 97-112.

[28] P. M. Favi, R. S. Benson, N. R. Neilsen, R. L. Hammonds, C. C. Bates, C. P. Stephens and M. S. Dhar, "Cell Proliferation, Viability, and in Vitro Differentiation of Equine Mesenchymal Stem Cells Seeded on Bacterial Cellulose Hydrogel Scaffolds," Materials Science and Engineering C, Vol. 33, No. 4, 2013, pp. 1935-1944. http://dx.doi.org/10.1016/j.msec.2012.12.100

[29] Q. Shi, Y. Li, J. Sun, H. Zhang, L. Chen, B. Chen, H. Yang and Z. Wang, "The Osteogenesis of Bacterial Cellulose Scaffold Loaded with Bone Morphogenetic Protein-2," Biomaterials, Vol. 33, No. 28, 2012, pp. 66446649.

http://dx.doi.org/10.1016/j.biomaterials.2012.05.071

[30] S. Saska, R. M. Scarel-Caminaga, L. N. Teixeira, L. P. Franchi, R. A. Dos Santos, A. M. M. Gaspar, P. T. de Oliveira, A. L. Rosa, C. S. Takahashi, Y. Messaddeq, S. J. L. Ribeiro and R. Marchetto, "Characterization and in Vitro Evaluation of Bacterial Cellulose Membranes Functionalized with Osteogenic Growth Peptide for Bone Tissue Engineering," Journal of Materials Science Materials in Medicine, Vol. 23, No. 9, 2012, pp. 2253-2266. http://dx.doi.org/10.1007/s10856-012-4676-5

[31] K. Hirayama, T. Okitsu, H. Teramae, D. Kiriya, H. Onoe and S. Takeuchi, "Cellular Building Unit Integrated with Microstrand-Shaped Bacterial Cellulose," Biomaterials, Vol. 34, No. 10, 2013, pp. 2421-2427. http://dx.doi.org/10.1016/j.biomaterials.2012.12.013

[32] C. S. Szot, C. F. Buchanan, P. Gatenholm, M. N. Rylander and J. W. Freeman, "Investigation of Cancer Cell Behavior on Nanofibrous Scaffolds," Materials Science and Engineering C, Vol. 31, No. 1, 2011, pp. 37-42. http://dx.doi.org/10.1016/j.msec.2009.12.005

[33] J. M. Taboas, R. D. Maddox, P. H. Krebsbach and S. J. Hollister, "Indirect Solid Free form Fabrication of Local and Global Porous, Biomimetic and Composite 3D Polymer-Ceramic Scaffolds," Biomaterials, Vol. 24, No. 1, 2003, pp. 181-194.

http://dx.doi.org/10.1016/S0142-9612(02)00276-4
[34] C. Martinez-Ramos, A. Valles-Lluch, J. M. Garcia Verdugo, J. L. Gomez Ribelles, J. Antonio Barcia, A. Baiget Orts, J. M. Soria Lopez and M. Monleon Pradas, "Channeled Scaffolds Implanted in Adult Rat Brain," Journal of Biomedial Materials Research Part A, Vol. 100A, No. 12, 2012, pp. 3276-3286.

[35] J. Wang, C. Yang, Y. Wan, H. Luo, F. He, K. Dai and Y. Huang, "Laser Patterning of Bacterial Cellulose Hydrogel and Its Modification with Gelatin and Hydroxyapatite for Bone Tissue Engineering," Soft Materials, Vol. 11, No. 2, 2013, pp. 173-180.

http://dx.doi.org/10.1080/1539445X.2011.611204

[36] J. C. Le Huec, T. Schaeverbeke, D. Clement, J. Faber and A. Le Rebeller, "Influence of Porosity on the Mechanical Resistance of Hydroxyapatite Ceramics under Compressive Stress," Biomaterials, Vol. 16, No. 2, 1995, pp. 113118. http://dx.doi.org/10.1016/0142-9612(95)98272-G

[37] L. Hong, Y. L. Wang, S. R. Jia, Y. Huang, C. Gao and Y. Z. Wan, "Hydroxyapatite/Bacterial Cellulose Composites Synthesized via a Biomimetic Route," Materials Letters, Vol. 60, No. 13-14, 2006, pp. 1710-1713. http://dx.doi.org/10.1016/j.matlet.2005.12.004

[38] Y. Z. Wan, L. Hong, S. R. Jia, Y. Huang, Y. Zhu, Y. L. Wang and H. J. Jiang, "Synthesis and Characterization of Hydroxyapatite-Bacterial Cellulose Nanocomposites," Composites Science and Technology, Vol. 66, No. 11-12, 2006, pp. 1825-1832.

http://dx.doi.org/10.1016/j.compscitech.2005.11.027

[39] A. I. Itala, H. O. Ylanen, C. Ekholm, K. H. Karlsson and H. T. Aro, "Pore Diameter of More than $100 \mathrm{mu}$ m Is Not Requisite for Bone Ingrowth in Rabbits," Journal of Biomedial Materials Research, Vol. 58, No. 6, 2001, pp. 679-683. http://dx.doi.org/10.1002/jbm.1069

[40] H. E. Gotz, M. Muller, A. Emmel, U. Holzwarth, R. G. Erben and R. Stangl, "Effect of Surface Finish on the Osseointegration of Laser-Treated Titanium Alloy Implants," Biomaterials, Vol. 25, No. 18, 2004, pp. 4057-4064. http://dx.doi.org/10.1016/j.biomaterials.2003.11.002

[41] V. V. Kancharla and S. C. Chen, "Fabrication of Biodegradable Polymeric Micro-Devices Using Laser Micromachining," Biomedical Microdevices, Vol. 4, No. 2, 2002, pp. 105-109. http://dx.doi.org/10.1023/A:1014679013888

[42] S. Chen, V. V. Kancharla and Y. Lu, "Laser-Based Microscale Patterning of Biodegradable Polymers for Biomedical Applications," International Journal of Materials and Product Technology, Vol. 18, No. 4-6, 2003, pp. 457468.

[43] C. A. Aguilar, Y. Lu, S. Mao and S. C. Chen, "Direct Micro-Patterning of Biodegradable Polymers Using Ultraviolet and Femtosecond Lasers," Biomaterials, Vol. 26, No. 36, 2005, pp. 7642-7649. http://dx.doi.org/10.1016/j.biomaterials.2005.04.053

[44] C. Gao, Y. Z. Wan, C. X. Yang, K. R. Dai, T. T. Tang, H. L. Luo and J. H. Wang, "Preparation and Characterization of Bacterial Cellulose Sponge with Hierarchical Pore Structure as Tissue Engineering Scaffold," Journal of Porous Materials, Vol. 18, 2011, pp. 139-145. http://dx.doi.org/10.1007/s10934-010-9364-6 
[45] V. Karageorgiou and D. Kaplan, "Porosity of 3D Biornaterial Scaffolds and Osteogenesis," Biomaterials, Vol. 26, No. 27, 2005, pp. 5474-5491.

http://dx.doi.org/10.1016/j.biomaterials.2005.02.002

[46] M. Flaibani and N. Elvassore, "Gas Anti-Solvent Precipitation Assisted Salt Leaching for Generation of Microand Nano-Porous Wall in Bio-Polymeric 3D Scaffolds," Materials Science and Engineering C, Vol. 32, No. 6, 2012, pp. 1632-1639. http://dx.doi.org/10.1016/i.msec.2012.04.054

[47] N. D. Evans, E. Gentleman and J. M. Polak, "Scaffolds for Stem Cells," Materials Today, Vol. 9, No. 12, 2006, pp. 26-33. http://dx.doi.org/10.1016/S1369-7021(06)71740-0

[48] B. J. Papenburg, J. Liu, G. A. Higuera, A. M. C. Barradas, J. de Boer, C. A. van Blitterswijk, M. Wessling and D.
Stamatialis, "Development and Analysis of Multi-Layer Scaffolds for Tissue Engineering," Biomaterials, Vol. 30, No. 31, 2009, pp. 6228-6239.

http://dx.doi.org/10.1016/j.biomaterials.2009.07.057

[49] A. A. Al-Munajjed, M. Hien, R. Kujat, J. P. Gleeson and J. Hammer, "Influence of Pore Size on Tensile Strength, Permeability and Porosity of Hyaluronan-Collagen Scaffolds," Journal of Materials Science Materials in Medicine, Vol. 19, No. 8, 2008, pp. 2859-2864. http://dx.doi.org/10.1007/s10856-008-3422-5

[50] E. Tsuruga, H. Takita, H. Itoh, Y. Wakisaka and Y. Kuboki, "Pore Size of Porous Hydroxyapatite as the CellSubstratum Controls BMP-Induced Osteogenesis," Journal of Biochemistry, Vol. 121, No. 2, 1997, pp. 317-324. http://dx.doi.org/10.1093/oxfordjournals.jbchem.a021589 